\title{
Fuzzy heuristic control of an electrodynamic shaker in accelerated HALT/ HASS tests
}

\section{Control heurístico difuso de un agitador electrodinámico en pruebas aceleradas de HALT / HASS}

\author{
Juliane Donadel $^{1} \quad$ Herbert Martins Gomes ${ }^{2 *}$ \\ Recibido 24 de noviembre de 2016, aceptado 19 de febrero de 2018 \\ Received: November 24, 2016 Accepted: February 19, 2018
}

\begin{abstract}
This study aims to develop and implement a control algorithm based on heuristic methods to be used in vibration-accelerated tests performed by an electrodynamic shaker for HALT (Highly Accelerated Life Tests) and HASS (Highly Accelerated Stress Screening). In such tests, these controllers should be robust to accommodate resonance effects in the test specimen and shaker that can affect the system's dynamics. Two control systems are designed: (i) a Fuzzy Logic Control and (ii) a traditional PID control, both implemented using an electrodynamic shaker to control mechanical stress and acceleration levels in a test specimen under HALT/HASS. The obtained experimental results show that both control systems presented similar behavior, occurring minor overshoots and negligible residual steady-state errors at both constant and sine sweep tests for acceleration and stress level control.
\end{abstract}

Keywords: PID control, fuzzy logic, heuristic control, electrodynamic shaker.

\section{RESUMEN}

Este estudio tiene como objetivo desarrollar e implementar un algoritmo de control basado en métodos heurísticos con el fin de ser utilizados en las pruebas acelerada de vibración realizados por un agitador electrodinámico para HALT (Highly Accelerated pruebas de vida) y HASS (Highly Accelerated Stress Screening). En estas pruebas, estos controladores deben ser robustos para dar cabida a los efectos de resonancia en la muestra de ensayo y agitador que pueden afectar a la dinámica del sistema. Dos sistemas de control están diseñados: (i) un control de lógica difusa y (ii) un control PID tradicional, tanto implementan utilizando un agitador electrodinámico con el fin de controlar los niveles de estrés y aceleración mecánicos en una muestra de ensayo bajo HALT/HASS. Los resultados experimentales obtenidos muestran que os dos sistemas de control presentan un comportamiento similar, aún que se producen sobre impulsos menores y los errores de estado estacionario residuales son insignificantes en ambas pruebas de vibración sinusoide constante y barrido para el control de la aceleración y el nivel de estrés mecánico.

Palabras clave: Control PID, lógica difusa, el control heurístico, agitador electrodinámico.

1 Instituto Federal de Educação. Ciência e Tecnologia do RS (IFRS). Campus Farroupilha. Av. São Vicente, 785. Farroupilha. RS, Brazil. E-mail: juliane.donadel@ farroupilha.ifrs.edu.br

2 Universidade Federal do Rio Grande do Sul (UFRGS). Rua Sarmento Leite, 425. $2^{\circ}$ andar. 90050-170. Porto Alegre. RS, Brazil. E-mail:herbert@mecanica.ufrgs.br

* Corresponding Author 


\section{INTRODUCTION}

Highly Accelerated Life Tests (HALT) and Highly Accelerated Stress Screening- (HASS) have gained supporters in the industry in the last decades. These techniques have been preferred over the usual Life Endurance Tests (LET), Design Verification Tests (DVT) and End of Production Tests (EPT) because they can rehearse not only products' parts, but also the product as a whole in several aspects. Products are subjected to load limits beyond values normally meet during their lifetime which enables improvement in reliability, reduction in warranty costs and increase customer satisfaction. HALT are usually performed with shakers in controlled temperature chambers in order to allow simultaneous vibration and thermal tests. It is important to obtain limit acceleration/stresses to which products (electronic components and automotive parts) can endure as the main vulnerability points [1]

The resonance condition is usually applied in HALT test so one can get large vibration amplitudes and therefore stress levels, to identify possible design flaws. HASS test can identify such critical points by a frequency screening using sine sweeps. Typical HALT-HASS environmental tests involve not only accelerated stress and vibration tests but also temperature, humidity, shock, corrosion, dust, solderability, etc.

The ability to monitor, control and record multiple channels for temperature, vibration, stresses are required for the testing equipment. The control system should ensure the required values during the entire test. The requirements for acceleration, for instance, may depend on the type of product, type of combined tests, application, etc. In the case of power conversion devices [3] and sine sweep test [1-2] the requirements are defined in terms of survival without permanent damage to a $0.75 \mathrm{~g}$ sinusoidal signal (zero to peak) from $5 \mathrm{~Hz}$ to $450 \mathrm{~Hz}$ at a rate of 1 octave per minute and secondary tests at the identified resonant frequencies during $10 \mathrm{~min}$.

Generally speaking, Fuzzy Controllers (FC) present the important feature of being flexible to the system's dynamics changes. Besides, they can easily embed expert knowledge and can be self-tuned since the control rules are stated in a linguistic way concerning inference rules [4-7]. The use of FC has been preferred to traditional controllers and received attention by many researchers in the last decade, such as [8-11] just to name a few.

There are several studies concerned in the development of controllers to perform vibration tests using electrodynamic shakers [12-16]. In particular, FC has been used in vibration test systems using electrodynamic shakers in different ways [17-18]. Rana [19] applied an FC sinusoidal acceleration amplitude test. They are produced by an electrodynamic shaker for specific tests in the aerospace and automotive industry. In this context, this paper aims at presenting the implementation of a control system based on fuzzy logic to control the mechanical stress and acceleration levels on a test specimen during constant and sine sweep tests using an electrodynamic shaker and compared with traditional discrete PID control method. The developed control is meant to be applied in HALT and HASS, which depend on the stress/acceleration levels. This implementation enables a robust control on the electrodynamic shaker that allows adapting to possible specimen resonance effects, which may change the system's dynamics, preventing controllers with fixed parameters to work efficiently. The novelty of the subject lies in the use of this type of heuristic controller to solve a practical problem of vibration control in mechanical systems, usually solved with traditional techniques such as discrete PID.

\section{Material and Methods}

In the implementation of the system, the Agilent VEE software was used for data processing [20] and Matlab software [21] for the fuzzy control implementation. Figure 1 shows the schematic configuration of the test rig and control system. The system is designed so that the mechanical stress produced by the shaker can be easily controlled and maintained during the specimen loading and unloading cycles in real time. The controller should also stabilize the system's stress and vibration levels in sine sweep frequency tests at accelerated fatigue life test. The specimen under test (SUT) is triangular shaped in such a way the measured deformation at any point of the surface is the same, reducing uncertainty in strain measurement by strain gauge placement. The specimen tip is pinned (free to rotate) by steel rollers and is clamped in the shaker's reaction frame. The vibration plate imposes prescribed displacements generating deformations and mechanical stress. 


\section{Electrodynamic shaker and equipment}

It was used an electrodynamic shaker TIRA St. 5000/300 model (Vibration Test Systems) with working frequency range $20-5000 \mathrm{~Hz}$ and 2940 $\mathrm{N}$ maximum force. These features give the shaker the ability to scan a wide frequency range with a maximum applied acceleration of about $35 \mathrm{~g}$. In tests for fatigue life, the shaker undergoes displacements cycles that are applied to the connected specimen, which in turn will experience a forced oscillating excitation. The object under test has mass, stiffness, and damping and can vibrate relative to the shaker's table. The shaker's base is rigidly fixed relative to the ground by a heavy concrete block and isolated to the surrounding by trenches. The measured FRF of the shaker shows a resonance near $5 \mathrm{~Hz}$ that represents the coupled system shaker-object under test. This allows using all the remaining upper-frequency range where the relationship between the applied voltage and the shaker's table displacement are linear. The use of a half Wheatstone bridge prevents thermal effects in the specimen in a simple bending situation, although the use of a full bridge would provide a gain that is twice the gain of the half-bridge for strain measurements at the expense of two new strain gauges'. Once there were several specimens, the use of full bridge would increase the total cost of the experimental setup. A TMDE Transdutec model signal conditioning and strain gauges model PA06-125AA-120-LEN with a nominal electrical resistance of $120 \Omega$ are used for strain measurements. It allows fine-tuning of the unbalance at half Wheatstone bridge by the use of knob controls at the front panel. So, prior to any experiment, it was verified the balance (Wheatstone bridge zero-volt output) by using the adjusting control knobs to attain zero voltage unbalance.

For acceleration measurements, ADXL203 accelerometers by Analog Devices are used. The acceleration limits are $\pm 1.7 \mathrm{~g}$ with a resolution of $1 \mathrm{mg}$, and frequency range $0.5 \mathrm{~Hz}$ to $2.5 \mathrm{kHz}$, with a constant nominal sensitivity of $970 \mathrm{mV} / \mathrm{g}$. Two different data acquisition boards were used: (a) USB A/D card 1208FS model (by Measurement Computing) with 12-bits, input range \pm 5 Volts and maximum sampling rate of $50 \mathrm{kHz}$; (b) sound card model Soundmax Integrated Digital HD Audio for the D/A conversion (by Analog Devices), with 16 bits, output range \pm 1.5 Volts and $48 \mathrm{kHz}$ maximum output sampling rate. A sampling rate of $48 \mathrm{kHz}$ was set for both systems. The use of two different data acquisition is justified by the different requirement in the control loop. For the sensor/acquisition part, the USB A/D card was used due to the number of channels that allowed acceleration and stress measurements (DC signals) at 12 bits simultaneously. For the actuator/control part, since the control signal is amplified with high gains values to drive the shaker, a more precise tune-up is necessary. This could not be achieved accordingly by the USB Card but by the sound card (AC signals, 16 bits).

\section{Tested specimen and stress level}

The tested specimen is a clamped-free triangular cantilever beam with length $L$ width $b$ and uniform thickness $t$, as shown in Figure 1. The tip displacement of the structure follows the same reasoning of the calculation for clamped-free cantilever beams with variable cross-section. The maximum equivalent force applied at the tip of the beam by an imposed displacement is. The displacement at the tip of the beam (load application point) and the stress on the face of the beam are related by . As the specimen is triangular-shaped, the stresses are the same at any point in their surface. Specifically, for the experimental tests $b_{0}=86 \mathrm{~mm}, L=92.57 \mathrm{~mm}, t=$ $2.01 \mathrm{~mm}, E=210 \mathrm{GPa}$ and Shaker's displacement limits is $\pm 6 \mathrm{~mm}$. Thus, the maximum stress is \pm 295 $\mathrm{MPa}$. The first three measured natural frequencies for the tested specimen in a clamped - free condition are: $1^{\text {st }}$ bending mode $406 \mathrm{~Hz}, 2^{\text {nd }}$ bending mode $1749 \mathrm{~Hz}, 1^{\text {st }}$ torsional mode $1834 \mathrm{~Hz}$. Therefore, in the frequency range of the experiments $(20 \mathrm{~Hz}-$ $1000 \mathrm{~Hz}$ ), only the $1^{\text {st }}$ bending mode of the specimen might affect the controller performance.

\section{IMPLEMENTED CONTROLLERS USED IN THE EXPERIMENTAL TESTS}

\section{PID controller}

The control signal generated by a PID controller is given by equation (1):

$$
u(t)=K_{p} e(t)+\frac{K_{p}}{T_{i}} \int_{0}^{\tau} e(\tau) d \tau+K_{p} T_{d} \dot{e}(t)
$$


(a)

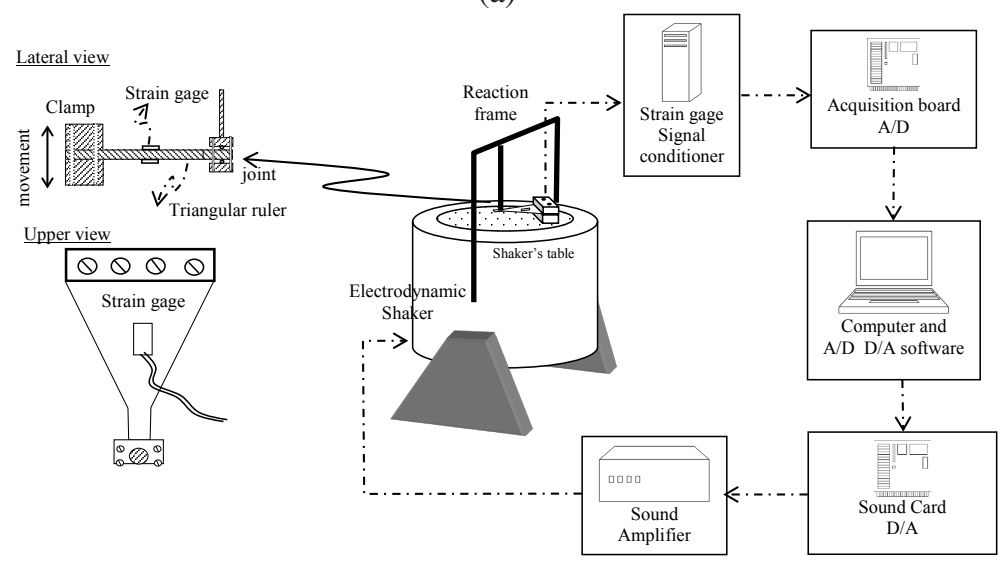

(b)

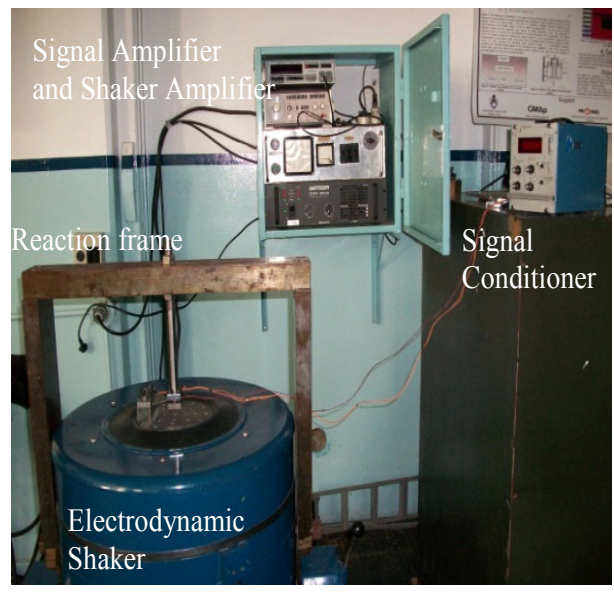

Figure 1. (a) Configuration of the control system. (b) Test rig with prototype, shaker and control system.

where $K_{p}$ is the proportional gain, $K_{p} / T_{i}$ is the integrative gain and $K_{p} T_{d}$ is the derivative gain ([22$23])$. The error is given by the difference between the reference value and the output of the system $e(t)=r-y(t)$, and the derivative of the error is given by $\dot{e}(t)=-\dot{y}(t)$. In the present case, the control loop allows control cycles of approximately $\Delta t \approx 86 \mathrm{~ms}$ that is implemented in a waveform-based control. Defining the output of the process, the reference signal, the control signal and the error at time $k \Delta t$, respectively as $y(k), r, u(k)$ and $e(k)$, equation (2) shows the corresponding implementation of the traditional discrete PID algorithm:

$$
\begin{aligned}
e(k)= & r-y(k) \\
u(k)= & u(k-1)+k_{p}[e(k)-e(k-1)]+\frac{k_{p} \Delta t}{T_{i}} e(k)+ \\
& +\frac{k_{p} T_{d}}{\Delta t}[e(k)-2 e(k-1)+e(k-2)]
\end{aligned}
$$

for sake of simplicity $e(k-1)$ and $e(k-2)$ are the error at $k-1$ and $k-2$ iteration steps of the recursive process.

The well-known heuristic tuning method of the reaction curve of the Ziegler-Nichols [24] is used as the initial controller parameter estimate, which was later fine-tuned by trial and error procedure in order to achieve the best performance [25]. Therefore, for each presented PID controller test, the Z-N method initial parameters were used and later finely adjusted for best performance.

\section{Fuzzy controller}

Four basic elements comprise a fuzzy logic controller: (i) a rule base, (ii) an inference mechanism, (iii) a fuzzification interface and (iv) a defuzzification interface [5-26]. Figure 2 shows these four 
elements. An FC may have as input, besides the error, the derivative and the integral of the error, similar to a traditional PID controller [28]. The proposed Fuzzy controller assumes the control law given by equation (3) and equation (4).

$$
\begin{gathered}
u(t)=u_{F}+\frac{K_{p}}{T_{i}} \int_{0}^{\tau} e(\tau) d \tau \\
u_{F}=F(e, \dot{e})
\end{gathered}
$$

where $u_{F}$ is the fuzzy control signal, that in this case plays the proportional and derivative roles and $K_{p}$ $/ T_{i}$ is the integrative gain.

The system inputs are chosen regarding the fuzzy sets: Positive (P), Zero (Z) and Negative (N). The outputs are chosen as Negative Big (NB), Negative Medium (NM), Zero (Z), Positive Medium (PM) e Positive Big (PB). The universe of discourse is the interval $[-1,1]$ volts, which are suitable limits as outputs for D/A conversion. The membership functions for the error $e$, error derivative $\dot{e}$, and control output $u_{F}$ are selected as basic triangles. In order to design the FC as general as possible, input and output gains were connected to the FC. This allows accommodating error and error derivatives of different orders of magnitude and the output of the FC to comply with the system's voltage physical limits. Therefore, for the error and error derivative there are $G_{e}$ and $G_{d e}$ gains, and for the output of the Fuzzy control signal, there is the $\mathrm{G}_{\mathrm{u}}$ gain ([4]). The rule database, in this case, is a matrix of order 2 , as shown in Table 1 ( $\dot{e}$ represents the derivative of the error). Since error and error derivative gains are attached to the FC, the rule database is defined as normalized membership functions with unit magnitude.
Following [27-28] recommendations an overlapping degree of 0.25 is chosen in order to give less fuzziness to the control signal outputs. For the output membership function, a value of 0.30 is used.

Table1. Fuzzy Rule base.

\begin{tabular}{|c|c|c|c|}
\hline $\begin{array}{c}e \text { (error) or } \\
e(\text { error derivative) }\end{array}$ & $\mathrm{N}$ & $\mathrm{Z}$ & $\mathrm{P}$ \\
\hline $\mathrm{N}$ & $\mathrm{NB}$ & $\mathrm{NM}$ & $\mathrm{Z}$ \\
\hline $\mathrm{Z}$ & $\mathrm{NM}$ & $\mathrm{Z}$ & $\mathrm{PM}$ \\
\hline $\mathrm{P}$ & $\mathrm{Z}$ & $\mathrm{PM}$ & $\mathrm{PB}$ \\
\hline
\end{tabular}

The rule base for the simulation of the PD controller follows that rule proposed by [29]. Table 1 is read in the following way: If the error is zero $(\mathrm{Z})$ and the derivative of error is positive $(\mathrm{P})$, then the control action (Gain) is positive medium (PM). The main function of the fuzzy inference engine is to calculate the total value of the control signal, based on the individual contribution of each rule of the rule database. The Mamdani inference operator is used for the aggregation of the rules [29]. The very popular centroid method is used for defuzzification, i.e., the center of mass of the resulted aggregated rules provides a unique crisp value for the control output [4].

\section{RESULTS}

\section{Controlling mechanical stress level at a fixed frequency}

The fuzzy and traditional PID controllers are compared in a single test applying oscillating mechanical stress of $20 \mathrm{kPa}$ at a fixed frequency of $50 \mathrm{~Hz}$ (these values complies with the limits for the specimen/material and shaker). Based on initial estimates from the Z-N

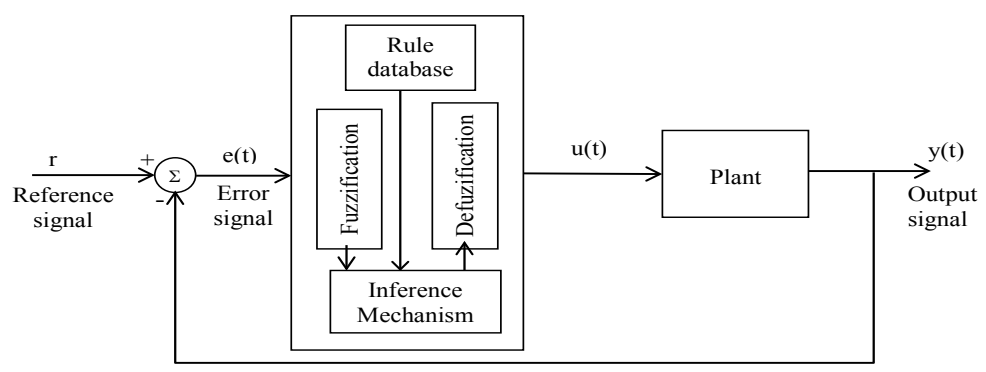

Figure 2. FC embedded into the control loop. 
method the PID parameters are fine-tuned to the best performance of the controller by trial and error. The parameters that best fit the PID controller system are and . For the fuzzy PD + I, it was found as best parameters for the controller and. The performance of both controllers for a step type input excitation is presented in Figure 3. Table 2 summarizes the test results obtained for both controllers for rising time and overshoot performance values.

Table 2. Comparisons between PID and FC for stress mechanical control with fixed stress and frequency (step input).

\begin{tabular}{|c|c|c|c|}
\hline & Rise Time (s) & Settling Time (s) & Overshoot (\%) \\
\hline PID Control & 0.23 & 0.6 & 2.8 \\
\hline FC & 0.60 & 1.0 & 2.4 \\
\hline
\end{tabular}

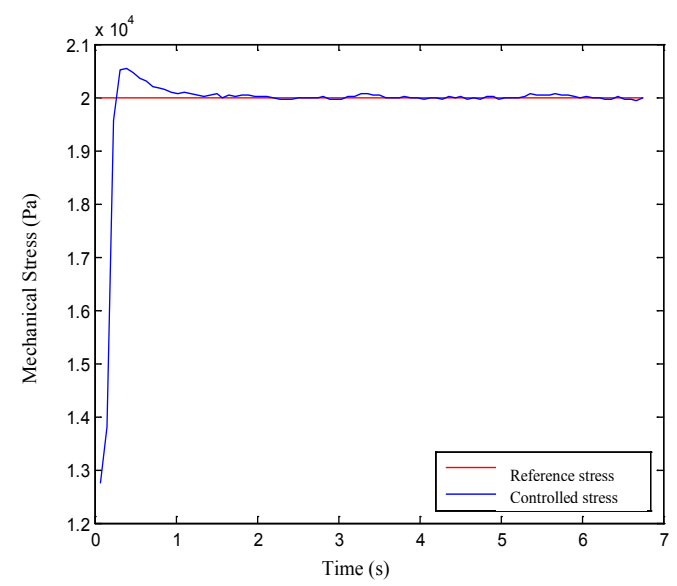

(a)

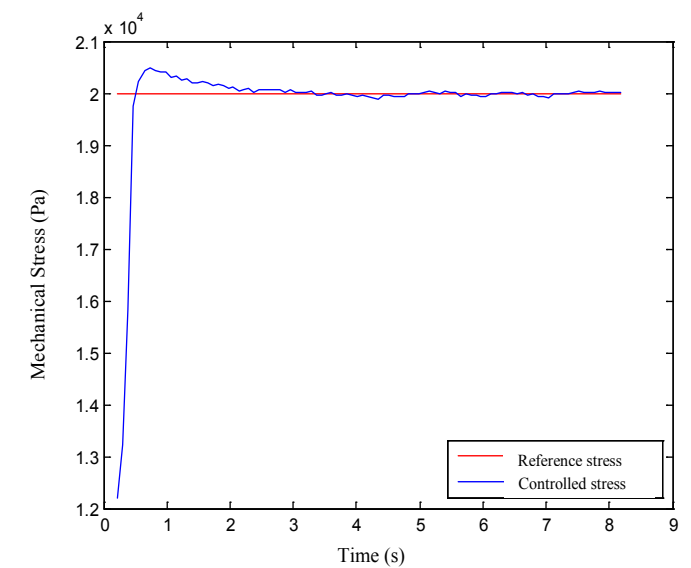

(b)

Figure 3. Controller performance for a fixed stress and frequency (step input): (a) PID and (b) Fuzzy PD+I
It can be noticed that PID control is faster, but has a higher overshoot compared to FC. However, Figure 3 shows that the differences are not significant along the time since both controllers are similarly effective controlling the stress level through time. In the following, a disturbance rejection test is applied to both controllers. The disturbance is obtained systematically by applying controlled variations in the shaker's amplifier gain $(+/-6 \mathrm{~dB})$. Figure 4 shows that the controlled PID stress signal returns to its reference value. However, in this case, the FC performs better, quickly becoming stable. The average time to the stabilization of the stress signal by the FC was 1.39 seconds and by the PID controller was 2.08 seconds. Besides, as indicated by Figure 4 , the FC presents few overshooting peaks, which also presented less magnitude than the traditional controller PID.

\section{Controlling the stress level at sine sweep test}

To perform the frequency sweep using the PID and the Fuzzy PD + I controllers, the sweep rate is fixed in 8 octaves per minute for the frequency range from $5 \mathrm{~Hz}$ to $1000 \mathrm{~Hz}$ and from $5 \mathrm{~Hz}$ to $200 \mathrm{~Hz}$. The reference mechanical stress was fixed at $8.4 \mathrm{kPa}$. The PID control parameters areand. Figure 5 shows the PID control signal along the frequency (a) from 5 $\mathrm{Hz}$ to $1000 \mathrm{~Hz}$ and (b) from $5 \mathrm{~Hz}$ to $200 \mathrm{~Hz}$. Figure 6 shows results with $\mathrm{FC}$ using the same values of the frequency range, sine sweep rate and mechanical stress level. Table 3 summarizes the tested cases.

Table 3. Comparisons of PID and FC for mechanical stress control with frequency sweep (5 to $1000 \mathrm{~Hz}$ ).

\begin{tabular}{|c|c|c|c|}
\hline & Rise Time (s) & Settling Time (s) & Overshoot (\%) \\
\hline PID Control & 0.63 & 0.63 & 13.0 \\
\hline FC & 0.93 & 0.93 & 17.0 \\
\hline
\end{tabular}

Analyzing Table 3, it can be concluded that the PID controller is faster. In both cases, the error and the error derivative remained very low (less than $0.1 \mathrm{kPa}$ ), confirming that the measured stress value is very close to the reference value and stays at that value (about 2\%) during the continuous frequency change. Due to limitations in the system (Shaker, amplifier, acquisition boards, etc.), it was only possible to control the mechanical stress on frequencies below $1000 \mathrm{~Hz}$. For wider frequency ranges, the control system failed to keep the signal at the reference value. 


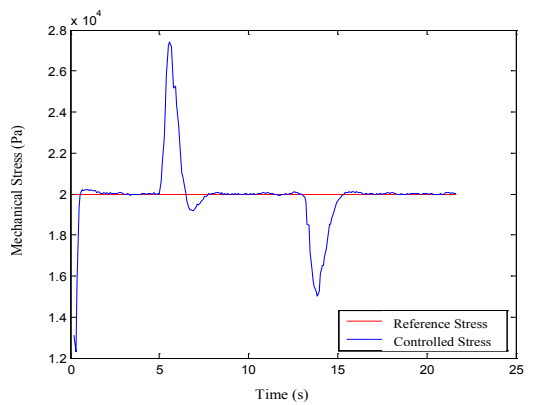

(a)

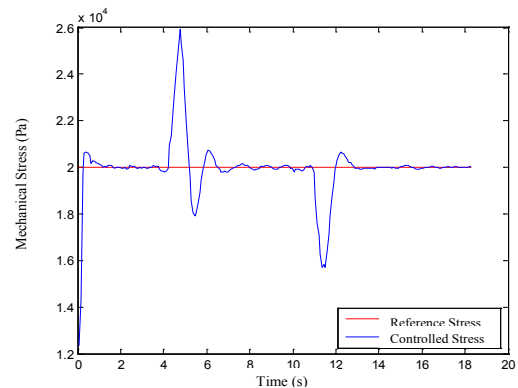

(b)

Figure 4. Disturbance rejection (+/- 6dB shaker's amplifier gain) with (a) Fuzzy PD + I and (b) PID controller.

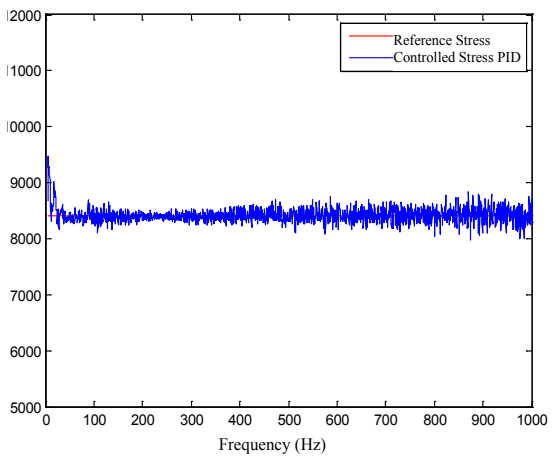

(a)

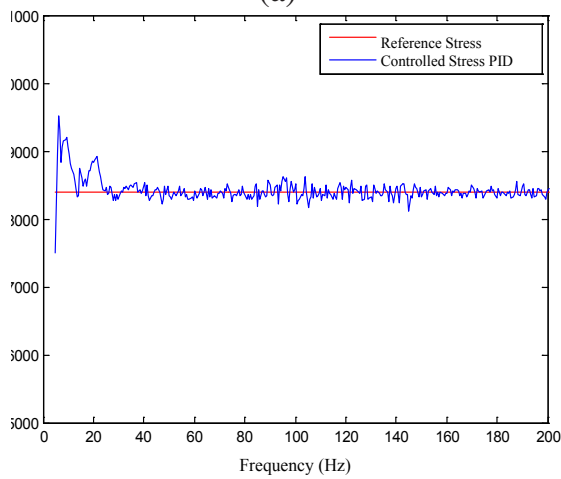

(b)

Figure 5. PID controller with frequency sweep (a) from $5 \mathrm{~Hz}$ to $1000 \mathrm{~Hz}$ and (b) from $5 \mathrm{~Hz}$ to $200 \mathrm{~Hz}$.
This is explained by the fact that for very high frequencies the shaker's table has to move at the same amplitude (to generate the same stress on the specimen) at large frequency (high-energy), making control not possible due to the force needed to move not only the specimen but also the shaker's table. In fact, the evaluated maximum force exceeds the limits for the equipment $\left(F_{\max }=2940 N\right)$.

The shaker's frequency upper limit is meant to be used with low displacement amplitudes (that is equivalent to low-stress levels). Therefore, as expected, there are limitations in the shaker operation related to the trade-off between frequency and stress level that is ruled by the maximum allowed force.

\section{Controlling acceleration levels at a fixed frequency}

For a fixed frequency and sinusoidal acceleration test using the PID controller, the obtained gain parameters are: and. The same parameters for the FC are: and . The fixed frequency used in the tests was $50 \mathrm{~Hz}$ and the desired value of the peak of sinusoidal acceleration was set as $0.4124 \mathrm{~g}$. Figure 7 shows the reference acceleration signal and the obtained signals using (a) traditional PID and (b) a FC.
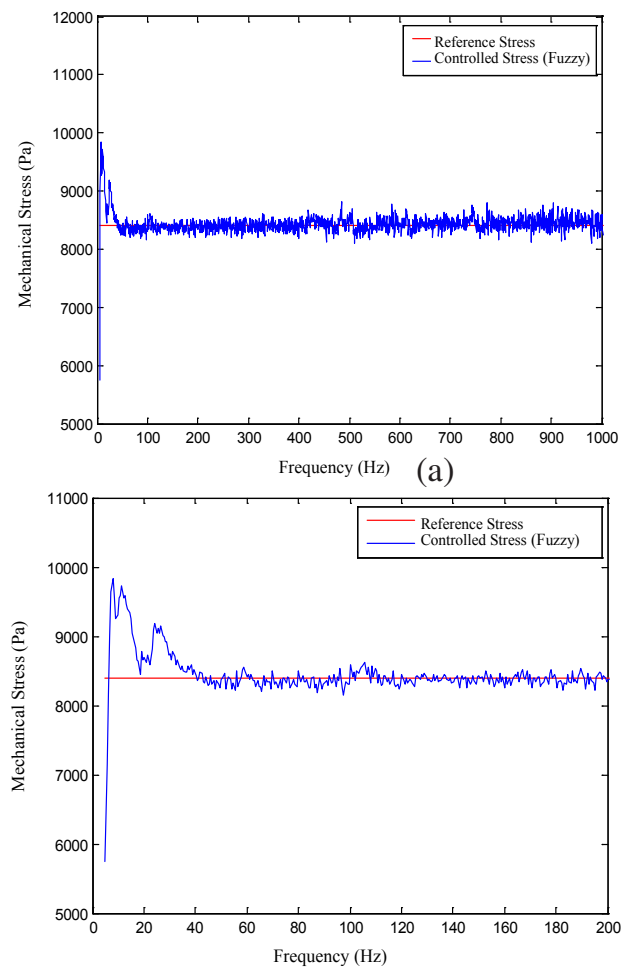

(b)

Figure 6. FC with frequency sweep (a) from $5 \mathrm{~Hz}$ to $1000 \mathrm{~Hz}$ and (b) from $5 \mathrm{~Hz}$ to $200 \mathrm{~Hz}$. 
Table 4 shows comparisons between the two controllers. Similarly, the PID control is slightly faster for the mechanical stress control with fixed frequency at $50 \mathrm{~Hz}$. Both did not present overshoot, which is less harmful to the specimen from a mechanical point of view. Both error and error derivative remains very low (about $0.01 \mathrm{~g}$ ) for both controllers and Figure 7 confirms the effectiveness of the controllers in this test.

Table 4. Comparisons of PID and FC for acceleration control with a fixed frequency $(50 \mathrm{~Hz})$.

\begin{tabular}{|c|c|c|c|}
\hline & $\begin{array}{c}\text { Rise Time } \\
(\mathrm{s})\end{array}$ & $\begin{array}{c}\text { Settling Time } \\
(\mathrm{s})\end{array}$ & $\begin{array}{c}\text { Overshoot } \\
(\%)\end{array}$ \\
\hline PID Control & 0.52 & 0.83 & 0.0 \\
\hline FC & 0.78 & 1.25 & 0.0 \\
\hline
\end{tabular}

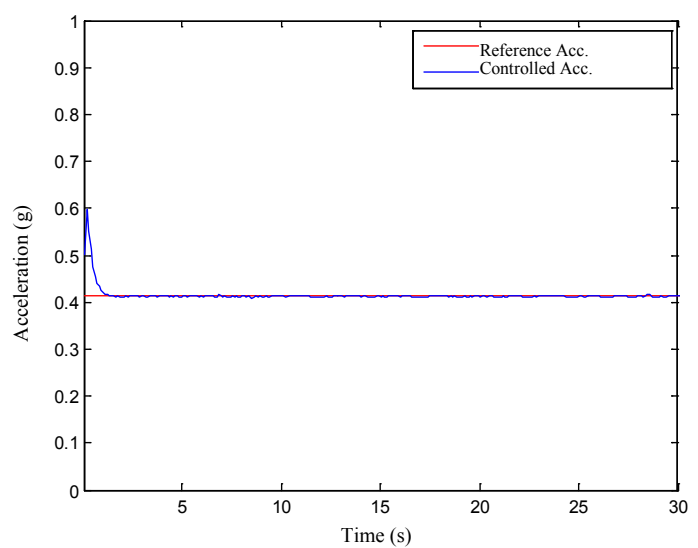

(a)

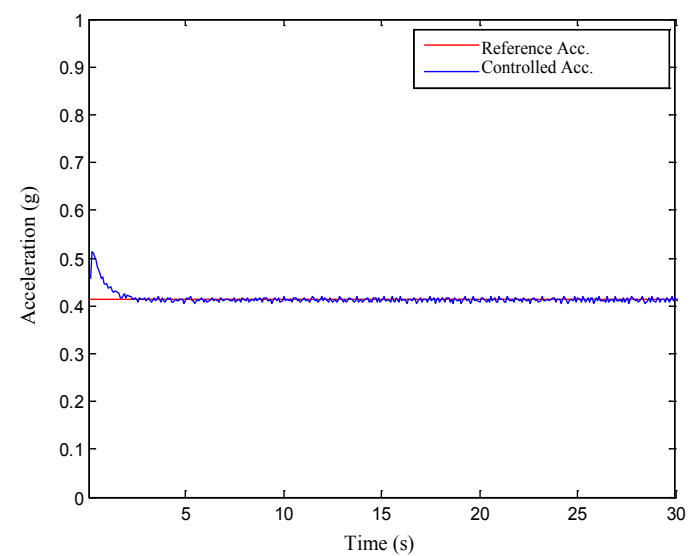

(b)

Figure 7. Controller behavior for fixed acceleration and frequency $(50 \mathrm{~Hz})$ with (a) PID and (b) FC.
Similarly to the stress level control test, it is performed a disturbance rejection test. The disturbance is applied in the same way for the stress test. Figure 8 shows the measured accelerations using (a) the PID controller and (b) FC.

The average time to stabilize after each disturbance for both PID and FC was about $0.90 \mathrm{~s}$ and $0.66 \mathrm{~s}$, respectively. Taking the frequency of vibration fixed, tests were conducted with both controllers by varying the peak acceleration amplitude (in increasing and decreasing steps). The acceleration peak value was varied from $0.1031 \mathrm{~g}$ to $0.8247 \mathrm{~g}$ in 4 steps and then returned to the initial value as shown in Figure 9. Table 5 summarizes the results for the performance values in this case.

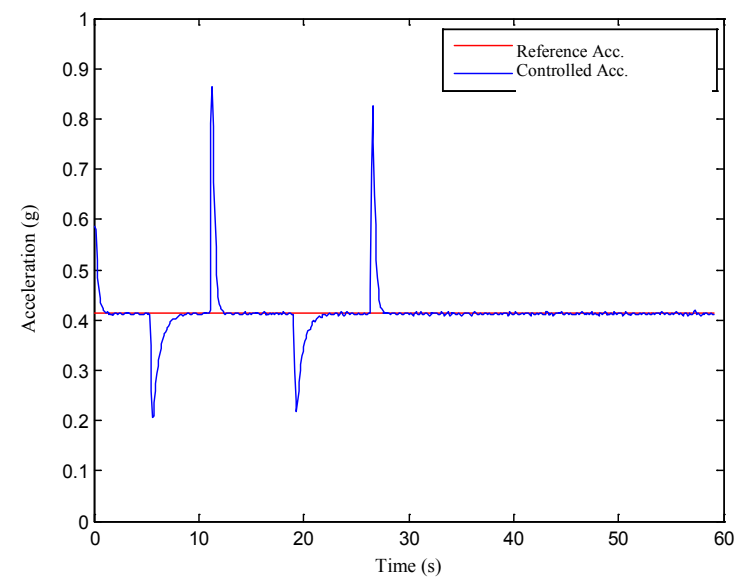

(a)

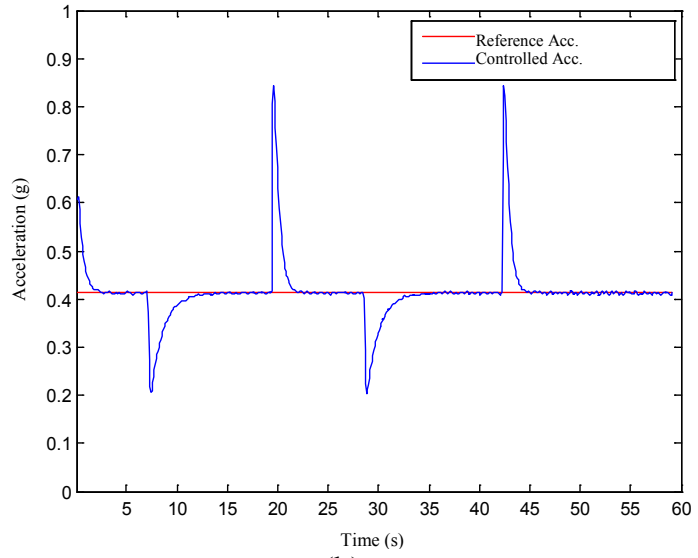

(b)

Figure 8. Disturbance rejection performance using (a) PID controller and (b) FC. 
Table 5. Comparisons for PID and FC for step acceleration changes with fixed frequency $(50 \mathrm{~Hz})$.

\begin{tabular}{|c|c|c|c|}
\hline & $\begin{array}{c}\text { Rise Time } \\
(\mathrm{s})\end{array}$ & $\begin{array}{c}\text { Settling Time } \\
(\mathrm{s})\end{array}$ & $\begin{array}{c}\text { Overshoot } \\
(\%)\end{array}$ \\
\hline PID Control & 0.55 & 0.55 & 20.0 \\
\hline FC & 0.55 & 0.55 & 13.5 \\
\hline
\end{tabular}

The values in Table 5 are averaged for each variation of the acceleration step amplitude. Comparing averaged overshoot and settling time for both Fuzzy and PID controllers, it is concluded that both have essentially the same behavior concerning time, and the FC presented slightly lower mean overshoot. Therefore, based on these experiments, it can be said that for amplitude control of sinusoidal waveform acceleration that varies in steps, at a constant frequency, the FC performed slightly better than PID.

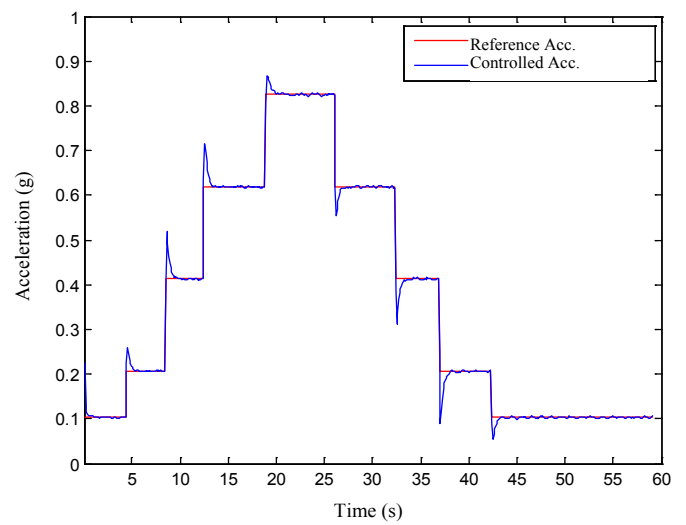

(a)

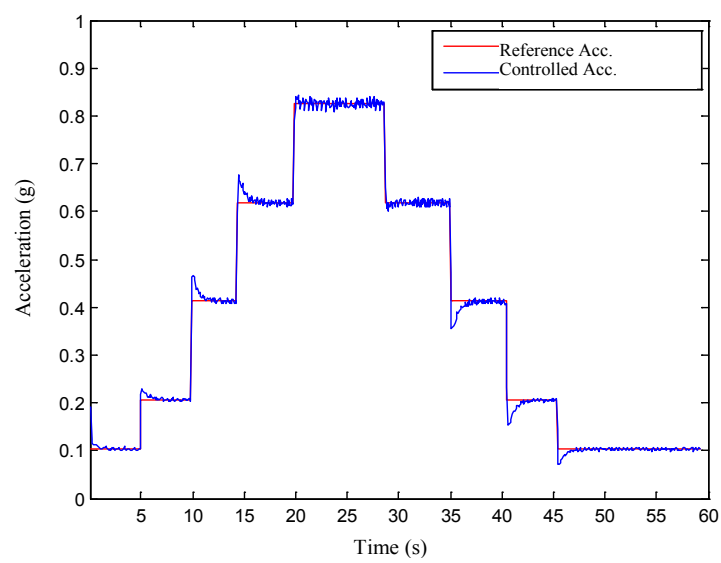

(b)

Figure 9. Control behavior at amplitude acceleration changes in steps for (a) PID controller and (b) FC.
Controlling acceleration levels at sine sweep tests The control of acceleration levels with frequency sweep is first performed using a PID controller with and and afterwards using a FC withand. The frequency sweeps from $5 \mathrm{~Hz}$ to $1000 \mathrm{~Hz}$ at eight octaves per minute and the reference value of the acceleration is set as 0.4124 g. Figure 10 shows the reference signal and the values obtained in the frequency axis for both controllers. Only the $1^{\text {st }}$. bending mode of the tested specimen might affect the controller performance in this frequency range; however, it did not affect significantly.

Figure 10 shows minor difficulties in controlling acceleration in the range of $400-500 \mathrm{~Hz}$ represented by low peaked acceleration values above the set point. Figure 10 reveals that the most 'critical' part for both controllers is the starting of the sweep since the system starts from the 'rest' and takes some time to stabilize, even with no significant change in frequency.

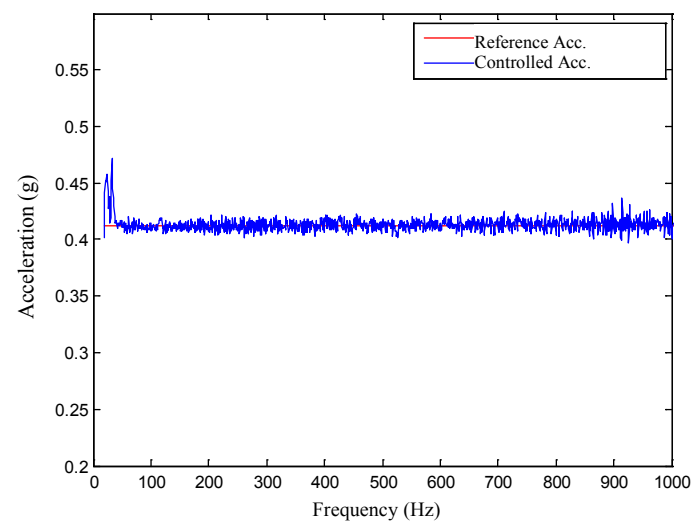

(a)

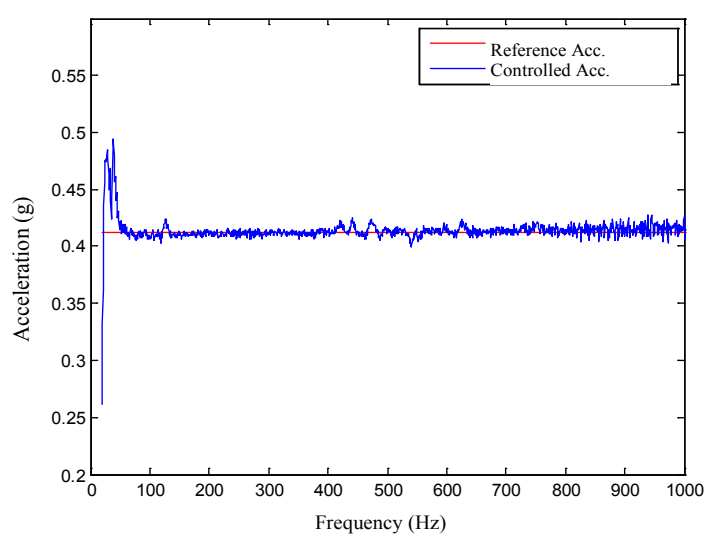

(b)

Figure 10. Controlled acceleration with the frequency sweep $(5 \mathrm{~Hz}-1000 \mathrm{~Hz}$ ) by (a) PID controller and (b) FC. 
Table 6 compares both methods through rising time, settling time and overshoot. In this case, the PID control behaves slightly better than the Fuzzy since all the parameters result lower than the FC ones. This behavior can also be explained by the fact that $5-20 \mathrm{~Hz}$ range is outside shaker's specifications (first natural frequency for the shaker's table).

Table 6. Comparisons of PID and FC for acceleration control with frequency sweep $(5 \mathrm{~Hz}-200 \mathrm{~Hz})$.

\begin{tabular}{|c|c|c|c|}
\hline & Rise Time (s) & Settling Time (s) & Overshoot (\%) \\
\hline PID Control & 2.7 & 2.7 & 11.0 \\
\hline FC & 3.7 & 3.7 & 17.0 \\
\hline
\end{tabular}

It is concluded that the presented results are very similar for the FC and PID controllers being satisfactory in an engineering point of view. However, the PID controller rise time was slightly faster for the start of the tests, when the shaker starts at a rest condition to a vibrating one. It is noteworthy that in the case of amplitude changes, apart from measurement uncertainties, the average time for rising time and settling time was practically the same for both controllers. In general, the FC presented a smaller overshoot than the PID, which is less impactful in terms of fatigue damage for the SUT.

\section{CONCLUSIONS}

In this paper, two types of control algorithms were designed to keep stable mechanical stress and acceleration levels in a metal specimen on accelerated tests with an electrodynamic shaker. The used control methods, PID and Fuzzy, were tested with fixed and sweep frequency sine waveforms cycles. Those tests are common in HALT/HASS accelerated tests for products. Both Fuzzy and PID controllers showed good results, where the control signals quickly converged to the reference value with a very low residual steady-state error, stabilizing in a short period, without significant overshoot, allowing the control of the acceleration and mechanical stress levels with accuracy in the SUT.

The experimental tests covered: (a) controlling specimen's mechanical stress levels at constant frequency, (b) controlling specimen's acceleration levels at constant frequency, (c) disturbance rejection to amplifier gain uncertainties, (d) step changes in acceleration, (e) mechanical stress at constant frequency and finally (f) controlling acceleration levels at sine sweep test. The controller gain varied slightly from one test to another and this prevented using only one set of the control parameter to all examples. Besides, the tests have different control variables that use different sensors (strain gages for stresses and accelerometers for accelerations) which changed the overall behavior of the system (different plants).

An observed relevant factor was the ability of both controllers to adapt to changes in the amplitude of the system by the disturbance rejection test. Both controllers quickly converged to the set point in acceleration or mechanical stress when a disturbance of $+/-6 \mathrm{~dB}$ is applied to the shaker's amplifier gain. This behavior was expected for the FC but unexpected for the PID controller since controller parameters are fixed and tuned to a different system in this case. Therefore, it can be concluded that the proposed Fuzzy control is at least as effective as a traditional PID control for HALT/HASS since both behave very similar.

Moreover, the heuristic control showed lower overshoot for step variation in acceleration, proving the effectiveness of both controllers to adapt to resonance effects caused by specimens. It is concluded that the proposed methodology can be applied for HALT/HASS tests (where large vibrations, and therefore stress, are expected) to identify possible design flaws that make product design modifications possible in a prototype phase.

\section{REFERENCES}

[1] P. Vassiliou and A. Mettas. "Understanding Accelerated Life-Testing Analysis". IEEE Proc. of Annual Reliability and Maintainability Symposium. pp. 1-14. 2003. DOI: 10.1.1.470.573.

[2] Military Specification. MIL-STD-202GMethod 204D. Test method standard: electronic and electrical component parts. Vibration, high frequency. Department of Defense. pp. 6. Febrero, 2002.

[3] British Standard. BS EN 60068-2-47:2005. Environmental testing. Tests. Mounting of specimens for vibration, impact and similar dynamic tests. pp. 38. 2005.

[4] J. Jantzen. "Foundations of Fuzzy Control: a practical approach". Wiley-Blackwell. 2. Ed., 2013. ISBN: 978-1-118-50622-6. 
[5] K.M. Passino and S. Yurkovich. "Fuzzy Control". Addison-Wesley Longman Inc.. 1997. ISBN: 020118074X.

[6] C.C. Lee. "Fuzzy Logic in Control Systems: Fuzzy Logic Controller-Part I". Proc. of the IEEE, Trans. on Systems, Man and Cybernetics. Vol. $20 \mathrm{~N}^{\circ}$ 2, pp. 440-418. 1990.

[7] A.I. Al-Odienat and A.A. Lawama. "The advantages of PID Fuzzy controllers over the conventional types". American Journal of Applied Sciences. Vol. $5 \mathrm{~N}^{\circ}$ 6, pp. 653-658. 2008. DOI: 10.3844/ajassp.2008.653.658.

[8] M.M.M. Salem and A.A. Ally. "Fuzzy Control of a Quarter-car Suspension System". International Journal of Aerospace and Mechanical Engineering. Vol. $4 \mathrm{~N}^{\circ} 4$, pp. 235-240. 2010.

[9] J. Kang and H-S. Kim. "Fuzzy hybrid control of a wind-excited tall building". Structural Engineering and Mechanics. Vol. $36 \mathrm{~N}^{\circ} 3$. 2010. DOI: $10.12989 / \mathrm{sem} .2010 .36 .3 .381$.

[10] H. Alli and O. Yakut. "Application of robust Fuzzy sliding-mode controller with Fuzzy moving sliding surfaces for earthquakeexcited structures". Structural Engineering and Mechanics. Vol. $26 \mathrm{~N}^{\circ}$ 5. 2007. DOI: 10.12989/sem.2007.26.5.517.

[11] H. Sharaiatmadar and H.M. Razavi. "Seismic control response of structures using an ATMD with the Fuzzy logic controller and PSO method". Structural Engineering and Mechanics. Vol. $51 \mathrm{~N}^{\circ}$ 4. 2014. DOI: 10.12989/sem.2014.51.4.547.

[12] Y. Xu and J. Chen. "Fuzzy control for geometrically nonlinear vibration of piezoelectric flexible plates". Structural Engineering and Mechanics. Vol. $43 \mathrm{~N}^{\circ} 2$. 2012. DOI: $10.12989 / \mathrm{sem} .2012 .43 .2 .163$.

[13] M.L. Wang. "Closed-Loop Random Vibration Control of a Shaker Table with a Microcomputer". Soil Dynamics and Earthquake Engineering. Vol. 13 Issue 4, pp. 259-325. 1994. DOI: 10.1016/0267-7261(94)90030-2.

[14] A. Girard, M. Pawlowski, P.E. Dupuis, L.P. Bugeat. "Prediction of the Control of a Sine Test on Electrodynamic Shaker. Spacecraft structures, materials, and mechanical testing". Proceedings of a European Conference. Braunschweig, Germany. 4-6 November 1998. Paris: European Space Agency (ESA),
ESA-SP. Vol. 428, pp.633-638. 1999. ISBN: 9290927127.

[15] L. Della Flora and H.A. Gründling. "Timedomain sinusoidal acceleration controller for an electrodynamic shaker". IET Control Theory and Applications. Vol. $2 \mathrm{~N}^{\circ} 12$, pp. 1044-1053. 2009. DOI: 10.1049/iet-cta:20080188.

[16] T.H. Chen and C.M. Liaw. "Vibration Acceleration Control of an Inverter-Fed Electrodynamic Shaker". IEEE/ASME Trans. on Mechatronics. Vol. 4 Issue 1, pp. 60-70. 1999. DOI: $10.1109 / 3516.752085$.

[17] Y. Uchiyama and M. Fujita. "Robust Acceleration and Displacement Control of Electrodynamic Shaker". Proc. of 2006 IEEE Int. Conf. of Control Application. Vol. 1 Issue 4, pp. 746-751. 2006. DOI: 10.1109/CACSDCCA-ISIC.2006.4776739.

[18] L. Xiangjun, G. Yanping, C. Xinzhong and M. Zhanjun. "Fuzzy PID Control of Acceleration for Electric Shaker". Proc. of 2010 International Conference on Measuring Technology and Mechatronics Automation, Vol. 2, pp. 333-336. 2010. DOI: 10.1109/ICMTMA.2010.577.

[19] K.P.S. Rana. "Fuzzy Control of an Electrodynamic Shaker for Automotive and Aerospace Vibration Testing". Journal of Expert Systems with Applications. Vol. $38 \mathrm{~N}^{\circ}$ 9, pp. 11335-11346. 2011. DOI: 10.1016/j.eswa.2011.02.184.

[20] Agilent Vee Pro 7.5. Agilent VEE Pro User's Guide. Agilent Technologies, Inc., $9^{\text {th }}$. Ed. 2005.

[21] Matlab version 7. Natick, Massachusetts: The MathWorks Inc. 2011.

[22] S. Bennett. "Development of PID Controllers". Proc. of IEEE Control Systems. Vol. 13 Issue 6. 1993.

[23] K. Ogata. "Modern Control Theory". Prentice Hall. $5^{\text {th }}$. Ed. 2009.

[24] J.G. Ziegler, N.B. Nichols. "Optimum settings for automatic controllers". Trans. of the ASME. Vol. 64, pp. 759-768. 1942.

[25] Burns and R.S. Advanced Control Engineering. Butterworth Heinemann. 2001.

[26] L.A. Zadeh. "Fuzzy Sets". Information and Control. Vol. 8, pp. 338-353. 1965.

[27] M. Mizumoto. "Fuzzy controls under various fuzzy reasoning methods". Information Sciences. Vol. 45 Issue 2, pp.129-151. 1988. 
[28] L. Reznik. "Fuzzy controllers handbook, How to design them, how they work". Newnes, pp. 240. 1997.

[29] E.H. Mamdani and S. Assilian. "An Ex- periment in Linguistic Synthesis with a Fuzzy Logic Controller". Int. Journal of Man-Machine Studies. Vol. 7 Issue 1, pp. 1-13. 1975. 